\title{
Microwave-Assisted Recycling Process to Recover Fiber from Fiberglass Polyester Composites
}

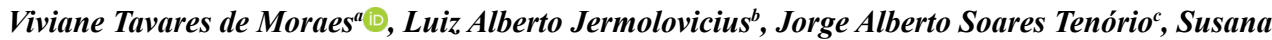

Marraccini Giampietri Lebrão ${ }^{a *}$, Guilherme Wolf Lebrão ${ }^{a}$ (D)

\author{
anstituto Mauá de Tecnologia, Centro Universitário, Departamento de Engenharia Mecânica, São \\ Caetano do Sul, SP, Brasil. \\ ${ }^{b}$ Instituto Mauá de Tecnologia, Centro Universitário, Laboratório de Micro-ondas, São Caetano do Sul, \\ SP, Brasil. \\ ${ }^{c}$ Escola Politécnica da Universidade de São Paulo, Departamento de Engenharia Química, São Paulo,
} SP, Brasil.

Received: June 18, 2019; Revised: December 19, 2019; Accepted: February 4, 2020

Fiberglass/thermoset matrix composite present important properties, such as specific mass and mechanical strength, aiming to replace some engineering materials. However, its mixture of different materials transforms them into an environmental problem, due to the complex recycling process. The highlight is meeting the demands of environmental pressures and for establishing recycling mechanisms, the proposal is to study physical recycling processes, focusing on the microwave-assisted pyrolysis process and also recovering fiberglass. The results were: humidity around $3 \mathrm{wt} . \%$; the average loss of mass around $68 \mathrm{wt} . \%$; the tensile strength is reduced by about $76 \%$ when a composite with recycled fiberglass is laminated, as compared to the use of virgin fiberglass. This work establishing the physical recycling mechanism and route for composite materials, identifying the thermal degradation processes, for thus applying them to other materials, still considered environmental issues, technically and economically making these materials manufacturing processes viable, as well as establishing a recycling route.

Keywords: Fiberglass, recycling, composites, polyester resin, microwave.

\section{Introduction}

The demand for lightweight structures in automotive, civil and aeronautic industries, with high strength, low cost and high structural performance started to be developed and improved over time ${ }^{1}$. Therefore, composite materials, especially fiberglass reinforced polyester, gained visibility and their production was increased. In 2018, the glass fiber to composites market reach 2.5 billion pounds in terms of volume and is expected to reach 3 billion pounds in $2024^{2,3}$.

The estimated compound growth rate will be $10 \%$ between 2018 and 2022 according to the Global fiber reinforced plastic report ${ }^{2}$.

The waste generated is classified as not hazardous residue and directly taken to landfills, originating $\mathrm{R} \$ 90$-million expense $^{2}$. Some alternatives like mechanical recycling ${ }^{4,5,6}$ and thermoset composites recycling have been investigated to related low cost and good properties ${ }^{7}$. The pyrolysis method is an alternative regarded to energy recovery coupled to the fiberglass recovery in composites ${ }^{8,9,10,11,12,13,14,15}$.

As from the aforementioned aspects, the present study aims to propose a solution technique for the waste-related issues and to find a way of reusing the composites by means of the microwave-assisted pyrolysis, allowing its sustainable consumption and preventing greater environmental liabilities.

One limiting aspect is the nature of the composite, largely constituted of a thermoset polymer and continuous

*e-mail: susana.lebrao@maua.br or discontinuous fibers. This type of polymer has covalent cross links which hinder its remodeling, as occurs in the recycling processes of the most common thermoplastics ${ }^{16}$.

The thermosettings polymers' recycling is usually difficult considering the cross-linked systems. Some studies ${ }^{16,17}$ shows different ways of recycling treatments. Some of them are incineration ${ }^{18}$; thermolysis process $^{19}$; mechanical recycling like granulation and comminution to incorporation in a thermoplastic matrix $x^{20,21,22}$ or in concrete ${ }^{23}$; solvolytic process $^{24}$, chemical recycling process ${ }^{25,26,27 .}$

Yang, et al. ${ }^{28}$ propose three recycling methods for thermoset matrix composites: mechanical; chemical and thermal.

The mechanical recycling process is the size reduction from composites by cutting or hammer mill, after size classification by a cyclone, which separates the fine particles to the recycling process ${ }^{29}$. But the investigation of this recycling process is to produce building materials with the same properties from virgin fiber $^{30,31}$.

In the chemical recycling can involve solvolysis ${ }^{32,33}$, hydrolysis ${ }^{28}$, glycolysis ${ }^{34}$ and acid digestion ${ }^{28}$, using solvent, water, glycols, and acid respectively. In this case, the process involves the chemical degradation or chemical dissolution to remove polymeric matrix. In this process, it can recover the matrix in the form of monomers or petrochemical feedstock by degradation and clear fibers ${ }^{35}$.

The thermal recycling process involves high temperatures which can include 3 types of operations ${ }^{28}$ : to recover energy only with incineration or combustion process; to recover 
energy and fiber to combustion recycling and fiber and fuel recovery to pyrolysis process. The pyrolysis processes can involve microwave-assisted recycling.

The microwave-assisted recycling is a physical process which consists in using thermal energy, heat, or a physical treatment so that the polymeric waste is degraded into basic components, such as monomers or other products, from which they can be recombined into new polymers or be used for other applications ${ }^{36}$. The recycling process using microwave is the physical process although the degradation which occurs in the microwave process is a chemical process, in this case, the thermolysis ${ }^{33}$.

Some methods used for thermal recycling are pyrolysis infused salt bath, pyrolysis at high temperatures and gasification. Thermal recycling requires high investments, which makes it viable only for large-scale operations, comparable to petrochemical industry operations ${ }^{28}$.

Microwave heating is totally different from the conventional one, by heat transfer. This type of heating is also called dielectric, with two different mechanisms. The first mechanism for transforming electromagnetic energy into heat is dipole rotation, whereby the molecules (with induced or permanent dipoles) are oriented in one direction according to the application of the magnetic field. After the magnetic field is removed, the energy absorbed by the molecule is liberated as heat. The other microwave-heating mechanism is called ionic conduction. The heat generated derives from losses by friction, which occurs by the migration of ions dissolved under the action of the electromagnetic field. For the most part, substances such as water, acetonitrile, and ethanol, polar substances in general, are good at absorbing microwaves. Conversely, less polar substances (aliphatic or aromatic hydrocarbons) absorb fewer microwaves. Other materials that do not absorb much are the highly ordinated crystalline materials. Teflon and type $\mathrm{S}$ glass are transparent to microwave ${ }^{37}$.

Using microwaves to provide the necessary heating for conducting pyrolysis proved to be very efficient in the pyrolysis of polyethylene, polyolefins, polystyrene and also of tires. Polymers are usually good microwave absorbers; therefore, so that they receive enough heat for pyrolysis, absorbent materials are added to the polymers, transmitting heat by conduction and reaching the necessary temperature ${ }^{38,39}$.

The micro-wave assisted pyrolysis advantage is the very fast thermal transfer enabling energy savings ${ }^{40}$. The most suitable solution to dispose fiberglass composites was considered the cement kiln rout, though in this process there is no way to recover products from the resin to reuse in new resins. The micro-wave assisted pyrolysis was classified like a not economically viable, but with this process it can be possible to recover fiberglass and valuable product after resin degradation to reuse in new resins in a very short time of pyrolysis ${ }^{40}$.

For fitting recycling, references present composites with thermoset matrixes as non-recyclable. Their use has thus faced great problems. Some technological solutions have already emerged for the technical viability of composite recycling.

The composite recycling does part of the European Union Directive 2000/53/EC which defines some management to the end-of-life vehicles (ELV) and hazardous substances ${ }^{41}$.

The pyrolysis process is considered environmentally friendly because i.e. the related to carbon fibers can produced fibers back with lower energy consumption. The energetic cost from produce virgin fibers is $183 \mathrm{MJ} / \mathrm{kg}$ to $286 \mathrm{MJ} / \mathrm{kg}$ while the waste fiber will consume around $7.5 \%+/-2.5 \%$ of the energy required and approximated $30 € / \mathrm{kg}$ from virgin fibers consumption ${ }^{42,43,44,45,46}$.

The purpose is to propose a recycling method for thermoset polyester fiberglass composite, aiming to reuse the reinforcement (fiberglass) into reusable residue, which implies a significant reduction of this material waste in landfills and also in the costs related to this issue.

\section{Materials and Methods}

A fiberglass/thermoset composite panel of $1.0 \mathrm{~m} \times 1.5 \mathrm{~m}$ was produced in the Polymer and Composite Laboratories of the Institute Maua of Technology.

This composite was prepared with 35 wt.\% chopped fiberglass and 65 wt.\% to orthophtalic resin, using MEKP (methyl ethyl ketone peroxide) catalyst. The virgin fiberglass used for manufacturing specimens was fabric, with $150 \mathrm{~g} /$ $\mathrm{m}^{2}$ grammage, without the addition of mineral load and UV stabilizer. The thickness plate was $3,00 \mathrm{~mm}+/-0,50 \mathrm{~mm}$.

This process occurs with a manual press. From this plate was taken the samples according to ASTM D3039. The manufacturing process was presented in Figure 1.

With the same process was manufacture the recycled fiberglass, with $35 \mathrm{wt} . \%$ to fiberglass and $65 \mathrm{wt} . \%$ to orthophtalic resin, using MEKP (methyl ethyl ketone) catalyst, thickness plate was $3.00 \mathrm{~mm}+/-0.50 \mathrm{~mm}$, the recycled fiberglass was laminated without aligned in a manual press. From this plate was taken the samples according to ASTM D3039.

The $2.5 \mathrm{GHz}$ microwave system assembled in the Microwave Laboratory of the Institute Maua of Technology, as shown in Figure 2 was used for the composite thermal degradation. This system comprises a high voltage source Figure $2 \mathrm{j}$ which feeds the microwave generator (Figure $2 \mathrm{i}$ ), connected to a waveguide (Figure $2 \mathrm{~g}$ ) and um directional coupler (Figure $2 \mathrm{f}$ ) to measure the power irradiated. This power is measured with a power meter (Figure $2 \mathrm{~h}$ ). For protecting the magnetron against the power reflected, a circulator is used (Figure 2e). This reflected power is measured by another directional coupler and absorbed by the water through the dissipative load (Figure 2c). The impedance matcher (Figure 2d) major function is to reduce the effective power sent to the cylindrical cavity (Figure 2b), which has a mobile and short end (Figure 2a).

Firstly, heating tests were required as it was an important parameter for the microwave set up electric power. In this 


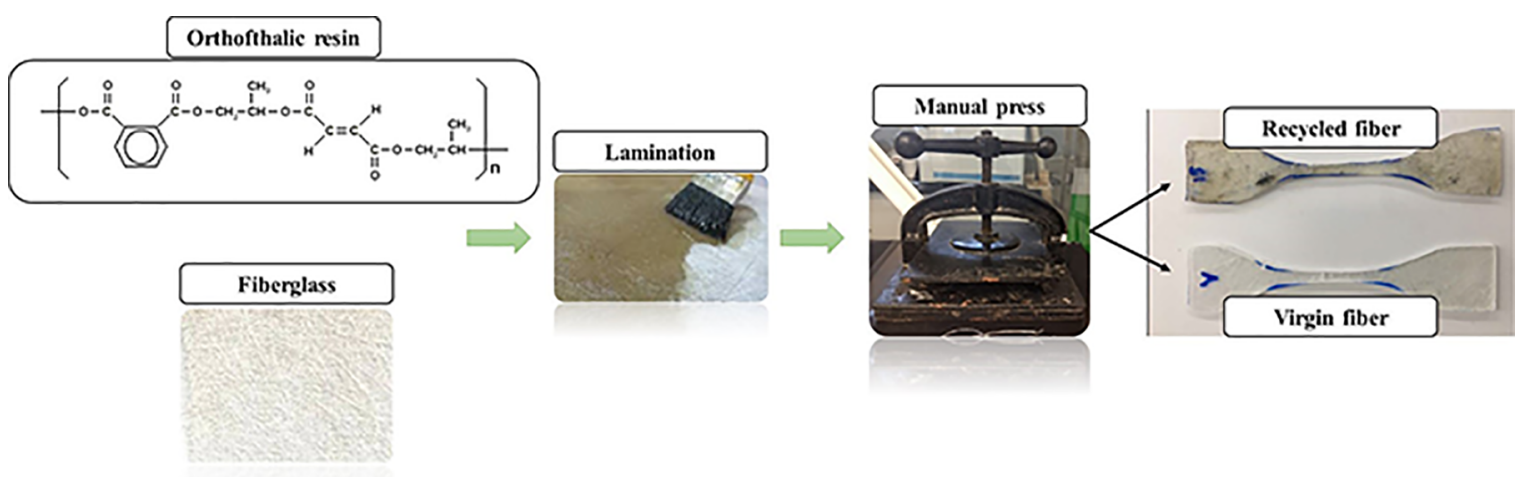

Figure 1. Fabrication of orthoftalic resin with recycled and virgin fiberglass composites

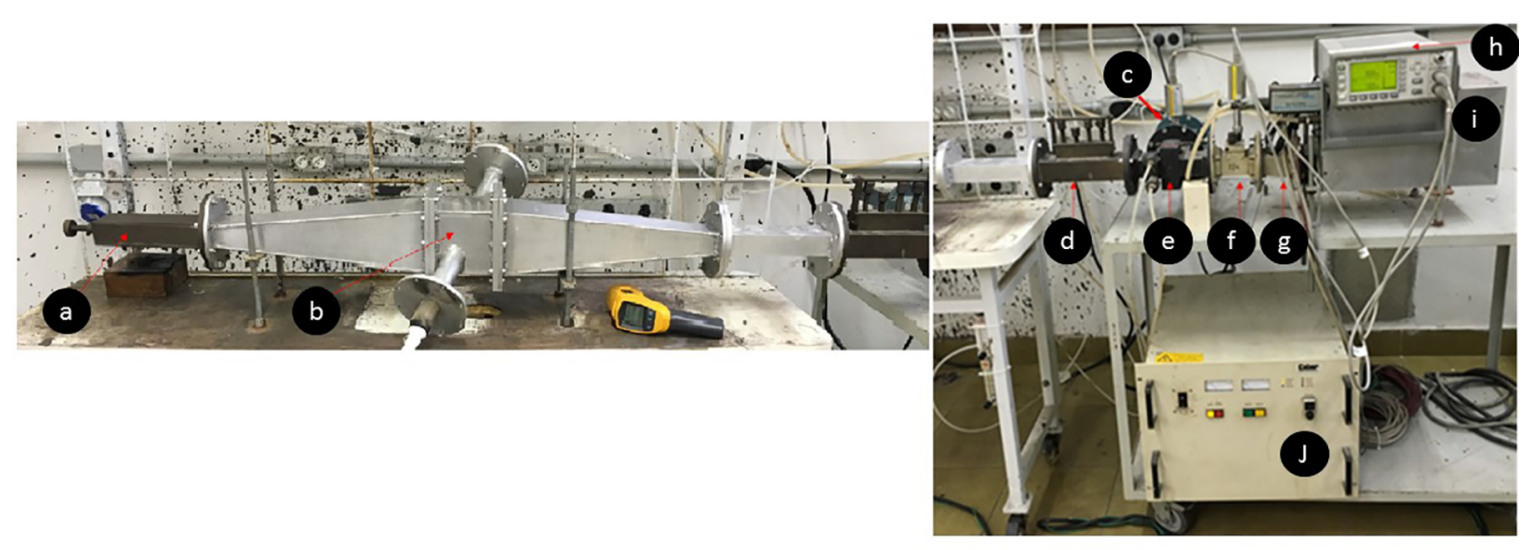

Figure 2. Microwave system at Instituto Mauá de Tecnologia

stage was performed for determining the humidity and burning in a muffle furnace, also for determining how much material was lost, also to determine how much material was lost, and the temperatures at which the occur the loss mass.

For determining the power, burning tests of samples of about $1.8 \mathrm{~g}$ were initially performed, with different values from $101 \mathrm{~W}$ to $558 \mathrm{~W}$ of the micro-wave, for thus determining a suitable power. With this selected power, 20 tests of 10 to 20 minute times were conducted to visually determine the best product. This process was adopted only to define suitable power from micro-wave. Due to execute the experiments was used $10 \mathrm{~g}$ samples of chopped fibers.

To better understanding what is happening, it was delimiting and optimizing the polyester composite with fiberglass micro-wave recycling process employing a central composite factorial planning $(\alpha=\sqrt{ } 2)$. To reduce the variability it was decided to study only two variables, the effective power (W) and the air flow going through the microwave cavity $\left(\mathrm{m}^{3} / \mathrm{h}\right)$. A preliminary test was performed based on the results from determining the power and the burning time, so as to set the limits at which this study would be applied. In the test, the entire recycling process described in the previous item was conducted, but varying the effective power of the micro-wave and determining the time necessary to reach the average a loss of mass also obtained in the previous test (about $70 \%$ ). The results are illustrated in Figure 3.

Figure 3 shows that from 11 to 17 minutes, the ratio effective voltage and burning time is represented by a curve, differently from the rest of the process, which is simply represented by a straight line. We thus decided to study, model and better understand this curve segment. The qualification of the fumes was not performed herein.

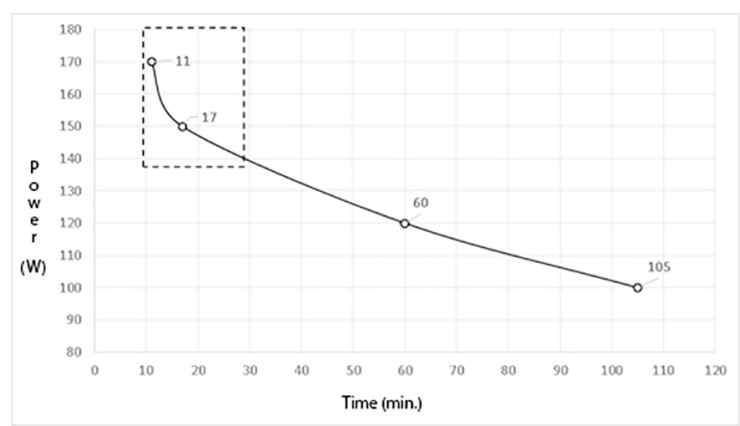

Figure 3. Power versus burning time

For the experimental planning, in this case, the limits of the variables must be defined, as displayed in Table 1 . To minimize the errors, ten repetitions were made for the 
central points. The air flow limits were defined based on the limit of operation of the rotameter and the compressor. In this process was done with air to determine the thermal degradation of condition to available fiberglass recover.

Table 1. Limits of the factorial test

\begin{tabular}{lcc}
\hline & Effective Power $(\mathbf{W})$ & Airflow $\left(\mathbf{m}^{\mathbf{3}} \mathbf{h}\right)$ \\
\hline$+\alpha$ & 188.28 & 1.28 \\
+1 & 180.00 & 1.13 \\
0 & 160.00 & 0.78 \\
-1 & 140.00 & 0.42 \\
$-\alpha$ & 131.72 & 0.28 \\
\hline
\end{tabular}

The response variables studied were loss of mass ( $\mathrm{m}_{\text {initial }} /$ $\mathrm{m}_{\text {final }}$ ) and time of visible fumes, which represents the polyester resin thermal degradation. Some equipment adaptations were made to control the air flow through the microwave cavity.

For performing the experiment, experimental planning was proposed, the limits of the effective microwaves power variables and the air flow were defined. The procedure basically constituted in adjusting the power and the air flow according to the factorial planning, introducing the $1.8 \mathrm{~g}$ sample with the aid of the ceramic adapted support of high alumina. According to the observation, the time of visible fumes was measure. The sample remained in the equipment for 30 minutes; it was then removed and weighed again, calculating the mass loss calculating.

So, a tensile test was done according to standard ASTM D3039 with recycled fiberglass and virgin fiberglass composites and the results performed was compared.

\section{Results and Discussion}

In burning tests for determining the power of micro-wave was calculated of percentage mass from humidity and loss of mass (determined in burning test), the media value $3 \mathrm{wt}$. $\%$ and 68 wt. $\%$, respectively.

The results from the power and the burning time were solely based on the visual aspect for obtaining a clean and light-colored fiber. For the voltage, at about $170 \mathrm{~W}$, all the polyester resin of the samples was observed to be eliminated at a level similar to the results from the preliminary test $(68$ wt. $\%$ of burning). After the voltage was identified, the times that corresponded to the total elimination of the resin were $11,12,13$ and $14 \mathrm{~min}$. Thus, a mass balance was conducted for the burning times (20 tests for each condition) and the results are presented in Table 2.

Figure 4 allows identifying the stages of the burning process, by images of the sample captured along the 11-minute test.

According to the numbering of the images, Figure $4 \mathrm{a}$ to $4 \mathrm{c}$ shows the moment at which the thermal degradation of the resin occurs, depositing residual materials in the fiber, causing the sample to darken.
Table 2. Results of the average loss of mass at different times

\begin{tabular}{lc}
\hline Time (min) & The average loss of mass (\%) \\
\hline 11 & 70 \\
12 & 71 \\
13 & 70 \\
15 & 71 \\
\hline
\end{tabular}

In Figure $4 \mathrm{~d}$ to $4 \mathrm{f}$, can be observed the decolored of samples. The test thermal degradation emitted the fumes of carbonization of the polymeric matrix and $\mathrm{CO}_{2}$ liberation, only the fiberglass remaining.

The results from the tests performed are represented in the graphs relating load ( $\mathrm{kgf})$ and displacement $(\mathrm{mm})$ in Figure 5, and the tensile strength of each sample in Table 3. Sample 1 and 2 (Figure 5a) were made of virgin fiberglass and sample A and B (Figure 5b) were made of recycled fiberglass.

The samples 1 and 2 (Figure 5a) from virgin fiberglass have media $1,139 \mathrm{kgf} / \mathrm{cm}^{2}$ while recycled fiberglass have media $266.5 \mathrm{kgf} / \mathrm{cm}^{2}$. The results from Figure 5 were used to calculate the tensile strength represented in Table 3.

The analysis of the results shows that the tensile strength is reduced by about $76 \%$ when a composite with recycled fiberglass is laminated, as compared to the use of virgin fiberglass.

According to Torres et $a l^{47}$ the mechanical properties of recycled fiberglass after the pyrolisys process of fiberglass polyester sheet molding compound was smaller the virgin fiberglass, the results showed the tensile strength around 18 $\mathrm{MN} / \mathrm{m}^{2}$ to $24 \mathrm{MN} / \mathrm{m}^{2}$. Comparing to sample A and B that represents the recycled fiberglass with results from Torres et $a l^{47}$ that is possible to see the correlation, because the recycled fiberglass developed by micro-wave pyrolysis is around 26.10 MN/m².

Another study publish by Giorgini et al. ${ }^{48}$ which evaluated the properties of recycled carbon fiber in epoxy resin describe the mechanical properties appear to be $65 \%$ to $95 \%$ of the initial values, the same was founded by Lee, Wei and Takahashi in various atmospheres ${ }^{49}$.

This is probably due to the degradation of the silane encapsulating the glass fibers, responsible for the adhesion of the resin to the fibers, and to the consequent transference of the stresses. For reusing the fibers, they have to be re-silanized. They would hence present better mechanical properties in the composites produced with them ${ }^{50,51,52}$.

The samples show an average Young Modulus of 47.0 $\mathrm{GN} / \mathrm{m}^{2}+/-1.5 \mathrm{GN} / \mathrm{m}^{2}$ for virgin material and a $23.0 \mathrm{GN} /$ $\mathrm{m}^{2}+/-7,2 \mathrm{GN} / \mathrm{m}^{2}$ for recycled ones. The recycled fiber has a half value of Young Modulus that the value from virgin fibers, which may characterize the loss of material stiffness, however that fiber still remain usable in many other no structural application ${ }^{28}$. In structural application cases some additional treatment was required ${ }^{40}$ 


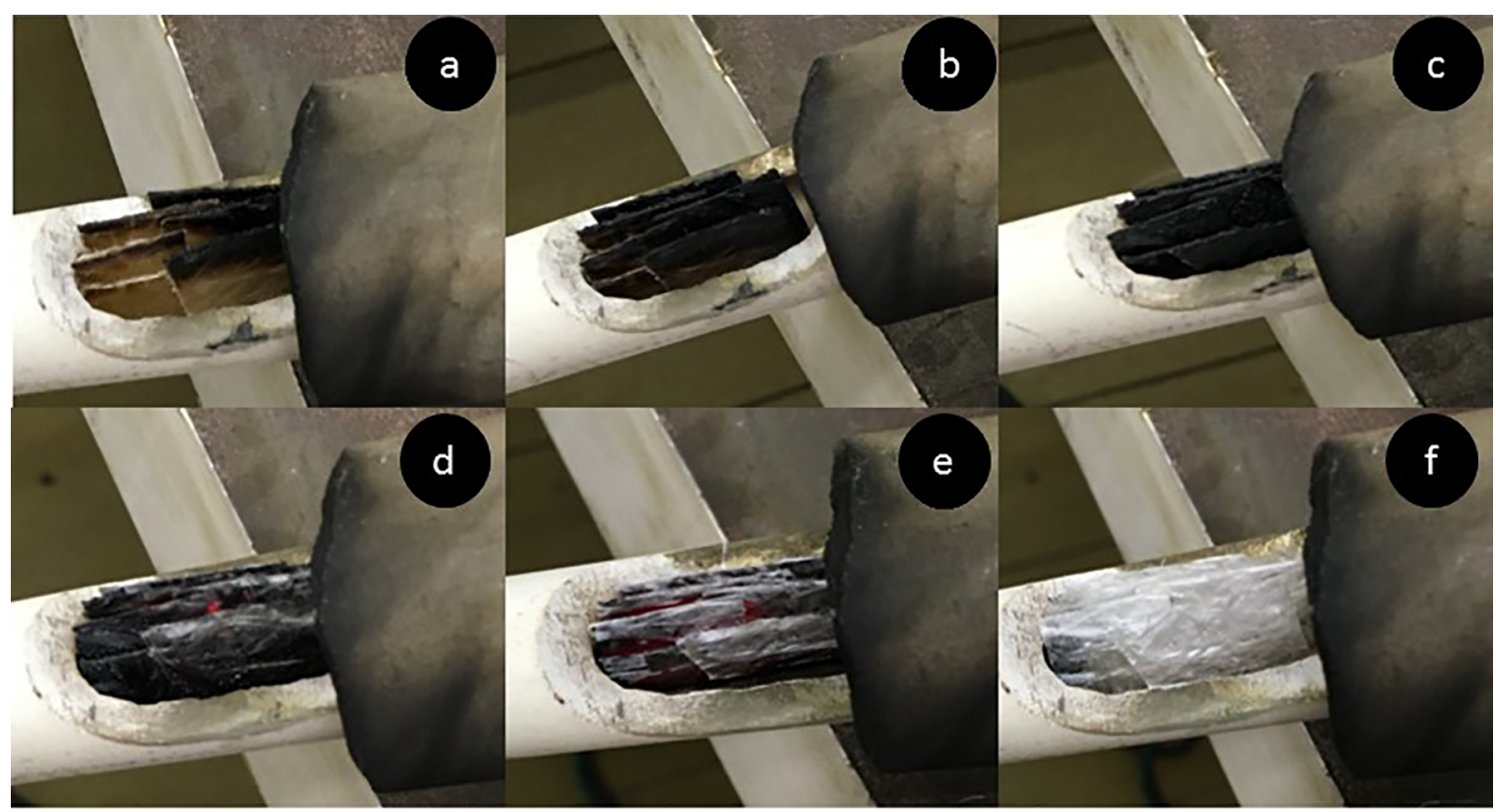

(a) 1 minute; (b) 3 minutes; (c) e minutes; (d) 7 minutes; (e) 9 minutes; (f) 11 minutes

Figure 4. Stages of the thermal degradation process

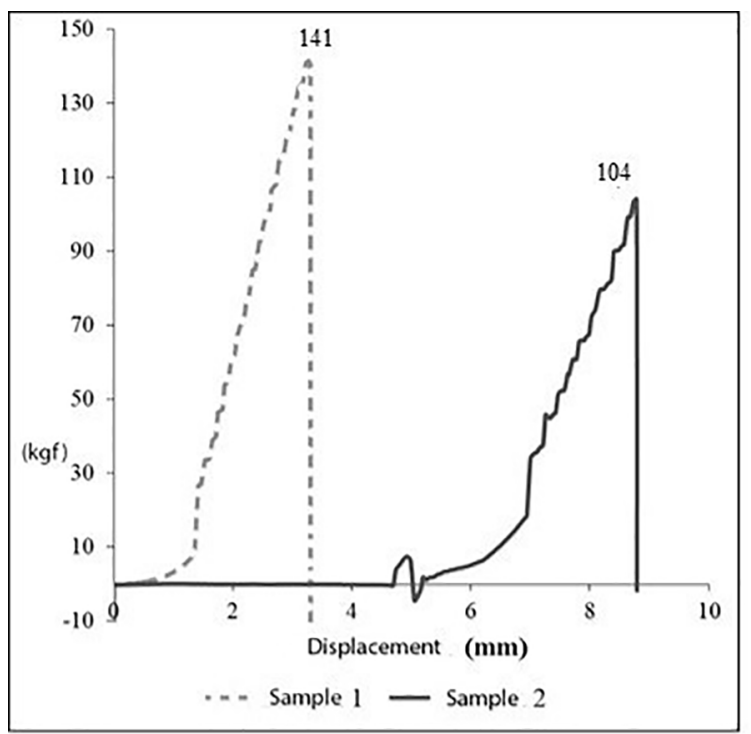

(a) Sample 1 and 2 were made of virgin fiberglass

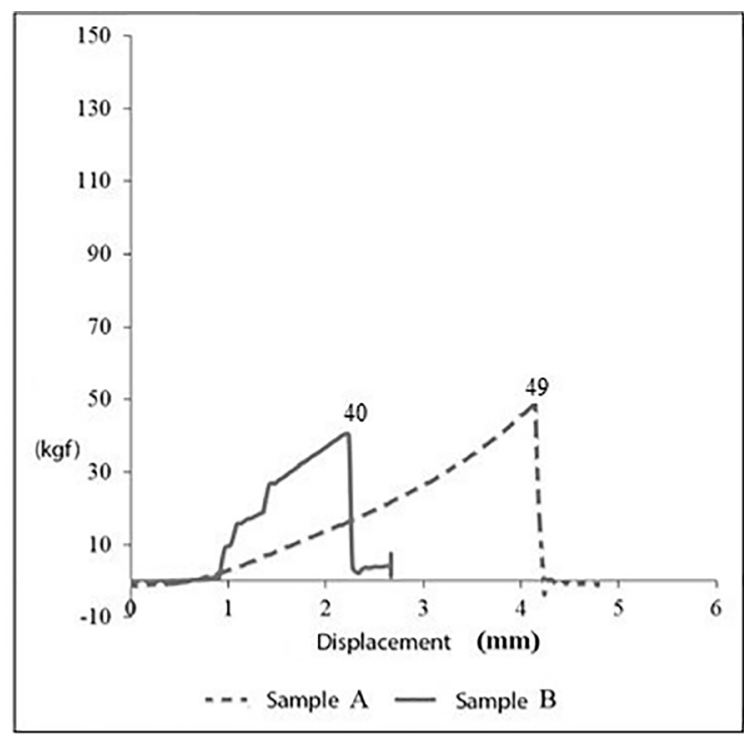

(b) Sample A and B were made of recycled fiberglass

Figure 5. Graphs of load in relation to the displacement of samples 1.2. A and B

Table 3. Results of the tensile tests for the different samples

\begin{tabular}{lcc}
\hline & Area $\left(\mathbf{m m}^{\mathbf{2}}\right)$ & Tensile Strength $\mathbf{( M N} / \mathbf{m} \mathbf{2})$ \\
\hline Sample 1 & 12.300 & 112.73 \\
Sample 2 & 9.210 & 110.67 \\
Sample A & 18.287 & 26.14 \\
Sample B & 15.120 & 26.13 \\
\hline
\end{tabular}

Studies from Mazzocchetti show that carbon fiber recycled cannot be used in the same original application, but it can be used in wide number of application as internal car panels, thermal insulation or parts witch mechanical properties are not essential but possibly a cheaper source of raw material, it also can be applied to the fiberglass recycled ${ }^{46}$. 


\section{Conclusions}

This work allowed concluding that it is possible to mitigate the impact of composite waste by means of the recycling process, based on burning irradiated by microwave, once the polymer matrix was fully eliminated by the heating at high temperatures, and the fiberglass was eventually isolated and free from the coke formed during the organic matter burning. The proposal herein generates a reduction of up to $73 \%$ of the waste volume, that is, the cost of dumping solid waste in an industrial landfill can be prevented, thus liberating the space the composite would occupy in the biosphere for about 50 years.

Under this study conditions, the fiberglass did not present adequate mechanical strength to be used for making new high quality composites, meantime offer a low cost fiber for a wide number of applications where other glass properties are very desirable. Yet it opens the possibility for optimizing the processing conditions so as to obtain a quality fiber comparable to the virgin fiber. Also indicated is the need to conduct a study on the calorific value of the fumes for its possible use as a secondary fuel. Even though the recycled fiber did not reach the desirable quality, after the process developed, it can be recycled in the glass industry, since it is completely separated from its organic matrix.

From the point of view of knowing the process of thermal degradation irradiated by microwaved composites, it was clear that there is a relationship between the air flow and the microwave power applied. The latter allows identifying that this work used an air flow heavier than that necessary. This reinforces the need for optimizing the processing conditions of this recycling.

The process proposed herein is more advantageous from the energy-saving viewpoint and for the reduction in greenhouse gas generation when compared to conventional thermal degradation. This is due to the microwave application having produced heating in the pyrolysis chamber region alone, not directly heating the reactor structure, which provides considerable energy saving.

\section{Acknowledgments}

This research work is supported by the Microwave Laboratory and Polymer and Composite Laboratories of the Institute Maua of Technology.

\section{References}

1. Reghunadhan A, Stranskowski M, Datta J, Kalarikkal N, Thomas S. Recycled polyurethane as a second phase in thermoset blends and its effect on thermal degradation kinetics studies. Macromolecular Symposia. 2018;382(1):1-10.

2. Mazumdar S. 2019 State of the Industry Report: the glass fiber market. Composites Manufacturing [Internet]. 2019; [cited 2019 oct 08]. Available from: http://compositesmanufacturingmagazine. com/2019/01/2019-state-of-the-industry-report

3. Sokoli HU, Simonsen ME, Nielsen PR, Arturi KR, Sogaard EG. Conversion of the matrix in glass fiber reinforced composites into a high heating value oil and other valuable feedstocks. Fuel Processing Technology. 2016;149:29-39.

4. Pickering SJ. Recycling technology for thermoset composite materials-current status. Composites Part A: Applied Science and Manufacturing. 2006;37(8):1206-1215.

5. Castro ACM, Ribeiro MCS, Santos J, Meixedo JP, Silva FJG, Fiúza A, et al. Sustainable waste recycling solution for the glass fibre reinforced polymer composite materials industry. Construction and Building Materials. 2013;45:87-94.

6. Castro ACM, Carvalho JP, Ribeiro MCS, Meixedo JP, Silva FJG, Fiúza A, et al. An integrated recycling approach for GFRP pultrusion wastes: recycling and reuse assessment into new composite materials using Fuzzy Boolean Nets. Journal of Cleaner Production. 2014;66:420-430.

7. Giorgini L, Leonardi C, Mazzocchetti L, Zattini G, Cavazzoni M, Montanari I. Pyrolysis of fiberglass/polyester composites: recovery and characterization of obtained products. FME Transactions. 2016;44(4):405-414.

8. Neri E, Berti B, Passarini F, Vassura I, Giorgini L, Zattini G, et al. Application of LCA methodology in the assessment of a pyrolysis process for tyres recycling. Environmental Engineering and Management Journal. 2018;17(10):2437-2445.

9. Palmer J, Ghita OR, Savage L, Evans KE. Successful closedloop recycling of thermoset composites. Composites: Part $A$. 2009;40:490-498

10. Giorgini L, Benelli T, Mazzocchetti L, Leonardi C, Zattini G, Minak G, et al. Pyrolysis as a way to close a CFRC life cycle: carbon fibers recovery and their use as feedstock for a new composite production. AIP Conference Proceedings. 2014;1599:354-357.

11. Yun YM, Seo MW, Koo GH, Ra HW, Yoon SJ, Kim YK, et al. Pyrolysis characteristics of GFRP (Glass Fiber Reinforced Plastic) under non-isothermal conditions. Fuel. 2014;137:321327.

12. Yun YM, Seo MW, Ra HW, Koo GH, Oh JS, Yoon SJ, et al. Pyrolysis characteristics of glass fiber-reinforced plastic (GFRP) under isothermal conditions. Journal of Analytical and Applied Pyrolysis. 2015;114:40-46.

13. Thomas S, Rane AV, Kanny K, Abitha VK, Thomas MG. Recycling of polyethylene terephthalate bottles - Plastics Design Library. New York: William Andrew; 2018.

14. Thomas S, Rane AV, Kanny K, Abitha VK, Thomas MG. Recycling of polyurethane foams - Plastics Design Library. New York: William Andrew; 2018

15. Kim JK, Saha P, Thomas S, Haponiuk JT, Aswathi MK. Rubber recycling: challenges and developments. London: Royal Society of Chemistry; 2018.

16. Gharde S, Kandasubramanian B. Mechanothermal and chemical recycling methodologies for the Fibre Reinforced Plastic (FRP). Environmental Technology \& Innovation. 2019;14(1):126. 
17. Thomas R, Vijayan P, Thomas S. Recycling of thermosetting polymers: their blends and composites. In: Fainleib A, Grigoryeva O. Recent developments in polymer recycling. India: Transworld Research Network; 2011. p. 121-153.

18. Scheirs J. Recycling of polymer composites. In: Scheirs J. Polymer recycling. New York: John Wiley \& Sons; 1998. p. 379-410.

19. Pickering SJ, Kelly RM, Kennerley JR, Rudd CD, Fenwick NJ. Fluidized-bed process for the recovery of glass fibres from scrap thermoset composites. Composites Science and Technology. 2000;60(4):509-23.

20. Bream CE, Hornby PR. Materials Science and Engineering. 2001;36:2965-75.

21. Reygrobellet JN. Recyclage de composites fibers de verrepolyester insaturé-carbonate de calcium par réincorporation dans des matrices thermoplastiques [thesis]. France: Montpellier University; 2000.

22. Kouparitsas CE, Kartalis CN, Vareilidis PC, Tsenoglou CJ, Papaspyrides CD. Recycling of the fibrous fraction of reinforced thermoset composites. Polymer Composites. 2002;23(4):682689.

23. Yamada K, Suenaga T, Mihashi H. Safe bending behavior of extrude mortar reinforced with CFRP. In: Proceedings of the 2nd International RILEM Workshop; 1995 oct 15-18; London, United Kingdom. London (UK): E. \& F. N. Spon; 1995. p. 157-167.

24. Paszun D, Spyjach T. Chemical recycling of poly (ethylene terephthalate). Industrial and Engineering Chemistry Research. 1997;36(4):1373-83.

25. Karsa DR. Chemical aspects of the plastics recycling. In: Proceedings of the Symposium on Chemical Aspects of Plastics Recycling; 1996 jul 3-4; Manchester (Great Britain). Manchester, Great Britain: UMIST; 1996.

27. Leaversuch RD. Polyolefins tailored for food containers and lids. Modern Plastics International. 1997;40:33-5.

28. Toselli M, Impagnaticllo M, Tramigioli C, Pilati F, Mazzoli G, Benuzzi G. Polymer Recycling. 1996;2:1-27.

29. Yang Y, Boom R, Irion B, Van Heerden DJ, Kuiper P, Wit H. Recycling of composite materials. Chemical Engineering and Processing: Process Intensification. 2012;51:53-68.

30. Mamanpush SH, Li H, Englund K, Tabatabaei AT. Recycled wind turbine blades as a feedstock for second generation composites. Waste Management. 2018;76:708-714.

31. Saccani A, Manzi S, Lancellotti I, Lipparini L. Composites obtained by recycling carbon fibre/epoxy composite wastes in building materials. Construction and Building Materials. 2019;204:296-302.

32. Medina NF, Garcia R, Hajirasouliha I, Pilakoutas K, Guadagnini M, Raffoul S. Composites with recycled rubber aggregates: Properties and opportunities in construction. Construction and Building Materials. 2018;188:884-897.

33. Arturi KR, Sokoli HU, Sogaard EG, Vogel F, Bjelic S. Recovery of value-added chemicals by solvolysis of unsaturated polyester resin. Journal of Cleaner Production. 2018;170:131-136.
34. Khalil YF. Comparative environmental and human health evaluations of thermolysis and solvolysis recycling technologies of carbon fiber reinforced polymer waste. Waste Management. 2018;76:767-778.

35. Zia KM, Bhatti HN, Bhatti IA. Methods for polyurethane and polyurethane composites, recycling and recovery: a review. Reactive and Functional Polymers. 2007;67:675-692.

36. Hirayama D, Saron C, Botello EC, Costa ML, Ancelotti Junior AC. Polypropylene composites manufactured from recycled carbon fibers from aeronautic materials waste. Materials Research. 2017;20(Suppl 2):519-525.

37. Aoudia K, Azem S, Hocine NA, Gratton M, Pettarin V, Seghar $\mathrm{S}$. Recycling of waste tire rubber: microwave devulcanization and incorporation in a thermoset resin. Waste Management. 2017;60:471-481.

38. Jermolovicius LA, Pouzada EVS, Nascimento RB, Castro ER, Senise JT, Mente BB, et al. Greening the green ethylene with microwaves. Chemical Engineering and Processing. 2018;127:238-248.

39. Undri A, Rosi L, Frediani M, Frediani P. Microwave assisted pyrolysis of corn derived plastic bags. Journal of Analytical and Applied Pyrolysis. 2014;108:86-97.

40. Beneroso D, Bermúdez JM, Arenillas A, Peña F, García JL, Pietro MA, et al. Oil fractions from the pyrolysis of diverse organic wastes: The different effects of conventional and microwave induced pyrolysis. Journal of Analytical and Applied Pyrolysis. 2015;114:256-264.

41. Oliveux G, Dandy LO, Leeke GA. Current status of recycling of fiber reinforced polymers: review of technologies, reuse and resulting properties. Progress in Materials Science. 2015;72:6199.

42. European Parliament (EP); Union, T.C.O.T.E. Directive 2000/53/ EC of the European Parliament of 18 September 2000 on end-of life vehicles. Official Journal of the European Union. 2000.

43. Baker DA, Rials TG. Recent advances in low-cost carbon fiber manufacture from lignin. Journal of Applied Polymer Science. 2013;130(2):713-728.

44. Song YS, Youn JR, Gutowski TG. Life cycle energy analysis of fiber-reinforced composites. Composites Part A: Applied Science and Manufacturing. 2009;40(8):1257-65.

45. Pimenta S, Pinho ST. Recycling carbon fibre reinforced polymers for structural applications: technology review and market outlook. Waste Management. 2011;31(2):378-92.

46. Witik RA, Teuscher R, Michaud V, Ludwig C, Manson JA. Carbon fibre reinforced composite waste: an environmental assessment of recycling, energy recovery and landfilling. Composites Part A: Applied Science and Manufacturing. 2013;49:89-99.

47. Mazzocchetti L, Benelli T, D’Angelo E, Leonardi C, Zttini G, Giorgini L. Validation of carbon fibers recycling by pyrogasification: the influence of oxidation conditions to obtain clean fibers and promote fiber/matrix adhesion in epoxy composites. Composites Part A: Applied Science and Manufacturing. 2018;112:504-514.

48. Torres A, Marco I, Caballero BM, Laresgoiti MF, Chomón MJ. Recycling of the solid residue obtained from the pyrolysis of 
fiberglass polyester sheet molding compound. Advances in Polymer Technology. 2009;28:141-149.

49. Giorgini L, Benelli T, Mazzocchetti L, Leonardi C, Zattini G, Minak G, et al. Recovery of carbon fibers from cured and uncured carbon fiber reinforced composites wastes and their use as feedstock for a new composite production. Polymer Composites. 2015;36(6):1084-1095.

50. Lee $\mathrm{H}$, Wei $\mathrm{H}$, Takahashi J. The influence of plasma in various atmospheres on the adhesion properties of recycled carbon fiber. Macromolecular Research. 2015;23(11):1026-1033.
51. Chua PS, Dai SR, Piggott MR. Mechanical properties of the glass fiber-polyester interphase Part I - Effects due to silane. Journal of Material Science. 1992;27:913-918.

52. Lapena MH, Marinucci G. Mechanical characterization of basalt and glass fiber epoxy composite tube. Materials Research. 2017;21(1):1-7.

53. Soares CJ, Santana FR, Pereira JC, Araujo TS, Menezes MS. Influence of airborne-particle abrasion on mechanical properties and bond strength of carbon/epoxy and glass/bis-GMA fiberreinforced resin posts. The Journal of Prosthetic Dentistry. 2008;99(6):444-454. 